\title{
Biological features of novel avian influenza A (H7N9) virus
}

Jianfang Zhou ${ }^{1 *}$, Dayan Wang ${ }^{1 *}$, Rongbao Gao ${ }^{1 *}$, Baihui Zhao ${ }^{2 *}$, Jingdong Song ${ }^{1}, X_{i a n ~}$ Qi $^{3}$, Yanjun Zhang ${ }^{4}$, Yonglin Shi ${ }^{5}$, Lei Yang ${ }^{1}$, Wenfei Zhu ${ }^{1}$, Tian Bai ${ }^{1}$, Kun Qin ${ }^{1}$, Yu Lan ${ }^{1}$, Shumei Zou ${ }^{1}$, Junfeng Guo ${ }^{1}$, Jie Dong ${ }^{1}$, Libo Dong ${ }^{1}$, Ye Zhang ${ }^{1}$, Hejiang Wei $^{1}$, Xiaodan Li ${ }^{1}$,

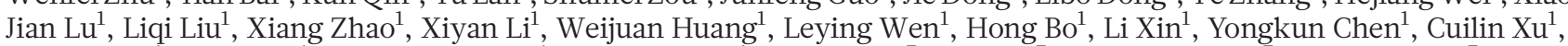
Yuquan Pei ${ }^{6}$, Yue Yang ${ }^{6}$, Xiaodong Zhang ${ }^{6}$, Shiwen Wang ${ }^{1}$, Zijian Feng ${ }^{7}$, Jun Han ${ }^{7}$, Weizhong Yang ${ }^{7}$, George F. Gao ${ }^{7}$, Guizhen Wu', Dexin $\mathrm{Li}^{1}$, Yu Wang ${ }^{7}$ \& Yuelong Shu ${ }^{1}$

Human infection associated with a novel reassortant avian influenza $\mathrm{H} 7 \mathrm{~N} 9$ virus has recently been identified in China ${ }^{1}$. A total of 132 confirmed cases and 39 deaths have been reported ${ }^{2}$. Most patients presented with severe pneumonia and acute respiratory distress syndrome $e^{3,4}$. Although the first epidemic has subsided, the presence of a natural reservoir and the disease severity highlight the need to evaluate its risk on human public health and to understand the possible pathogenesis mechanism. Here we show that the emerging $\mathrm{H} 7 \mathrm{~N} 9$ avian influenza virus poses a potentially high risk to humans. We discover that the H7N9 virus can bind to both avian-

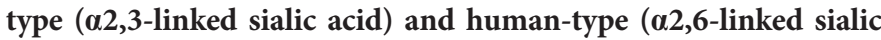
acid) receptors. It can invade epithelial cells in the human lower respiratory tract and type II pneumonocytes in alveoli, and replicated efficiently in ex vivo lung and trachea explant culture and several mammalian cell lines. In acute serum samples of H7N9infected patients, increased levels of the chemokines and cytokines

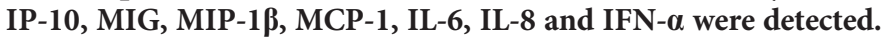
We note that the human population is naive to the H7N9 virus, and current seasonal vaccination could not provide protection.

In February 2013, a novel avian influenza H7N9 virus emerged in China and was found to infect humans ${ }^{1}$. As of 31 May 2013, a total of 132 human infections and 39 fatal cases have been identified ${ }^{2}$. Most cases have occurred among elders who were considered to be at increased risk for influenza complications because of age immunity and/or underlying medical conditions ${ }^{4}$. In contrast to other previous human $\mathrm{H} 7$ infections that mainly manifested mild illness or conjunctivitis, most H7N9 patients were critically ill and presented severe pneumonia and acute respiratory distress syndrome ${ }^{1,3,4}$. Sequence analysis of the avian influenza A (H7N9) virus indicates that it possesses several genetic features contributing to its ability to infect humans, and raises concerns about the pandemic potential ${ }^{1}$. Therefore, to evaluate its risk on human public health and understand the possible pathogenesis mechanism, we investigated the biological features of the H7N9 virus and the host immunity of infected patients as well as the general human population.

It is generally accepted that haemagglutinin-receptor-binding preference to $\alpha 2,6$-linked (human-type) sialylated glycans is the initial key step for a novel influenza-virus-causing pandemic. First, we tested the receptorbinding property of the novel H7N9 viruses (A/Shanghai/1/2013 (SH1), A/Shanghai/2/2013 (SH2), and A/Anhui/1/2013 (AH1)) using glycan dose-dependent binding assays as described previously ${ }^{5}$. We discovered that the viruses bound to both avian-type $(\alpha 2,3)$ and human-type $(\alpha 2,6)$ receptors, whereas avian influenza H5N1 (A/Anhui/01/2005) and pandemic H1N1 (A/California/07/2009) viruses preferentially bound to $\alpha 2,3$ and $\alpha 2,6$ receptors respectively, as expected (Fig. 1). The enhanced 22,6-binding of H7N9 may attribute to single or multiple substitutions in haemagglutinin including Ala138Ser in SH1 or Gly186Val and Gln226Leu in both SH2 and AH1, as reported elsewhere ${ }^{6-11}$. The presence of alanine at residue 160 in haemagglutinin of all three viruses resulted in a glycosylation loss and had been observed to increase the affinity of the H5N1 virus for human-type receptors ${ }^{12,13}$. Furthermore,

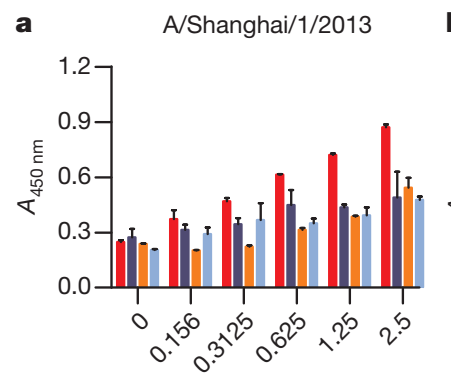

Sialyglycopolymer concentration $\left(\mu \mathrm{g} \mathrm{ml}^{-1}\right)$

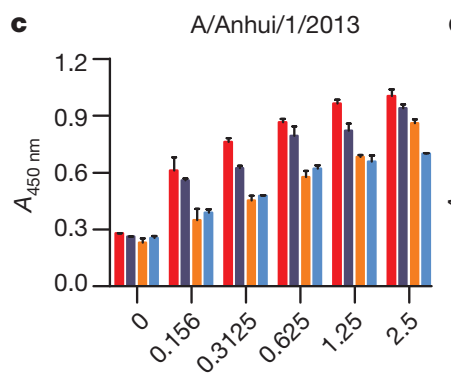

Sialyglycopolymer concentration $\left(\mu \mathrm{g} \mathrm{ml}^{-1}\right)$

\section{3'SLN}

b $\quad \mathrm{A} /$ Shanghai/2/2013

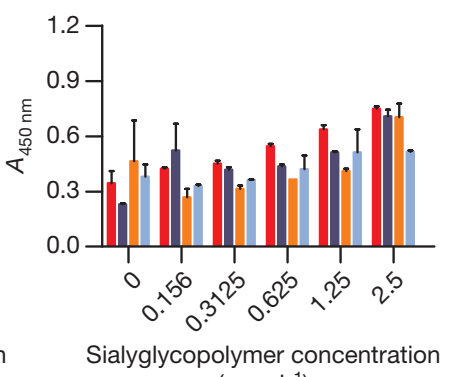
$\left(\mu \mathrm{g} \mathrm{ml}^{-1}\right)$ d

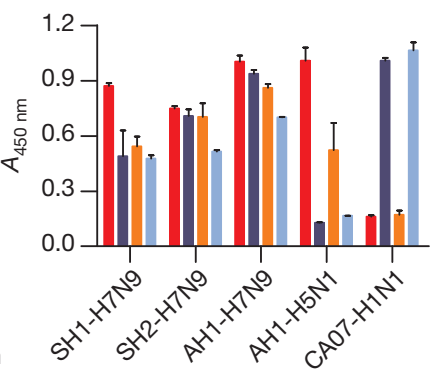

3'SLN-LN

6'SLN-LN

Figure $1 \mid$ Receptor binding properties. a-c, Dose-dependent binding of A/Shanghai/1/2013 (a), A/Shanghai/2/2013 (b) and A/Anhui/1/2013 (c) viruses to both $\alpha 2,3$ and $\alpha 2,6$ glycans at the concentration of $0,0.156,0.3125,0.625,1.25$ and $2.5 \mu \mathrm{g} \mathrm{ml}^{-1}$ sialylglycopolymers. d, The binding pattern of H7N9, H5N1 (A/Anhui/01/2005) and pandemic H1N1 (A/California/07/2009) viruses were exhibited at $2.5 \mu \mathrm{g} \mathrm{ml}^{-1}$. H5N1 data were obtained previously, as $\mathrm{H} 5 \mathrm{~N} 1$ and H7N9 viruses cannot be simultaneously handled owing to biosafety reasons. Results denote mean \pm s.e.m. from two separate assays performed in duplicate. 3'SLN, Neu5Ac $\alpha 2-3$ Gal $\beta 1-4 G l c N A c ; 3$ 'SLN-LN, Neu5Ac $\alpha 2-3(\mathrm{Gal}$ $\beta 1-4$ GlcNAc $\beta 1-3)_{2}$; 6'SLN, Neu5Ac $\alpha 2-6$ Gal $\beta 1-4 G l c N A c ; 6$ 'SLN-LN, Neu5Ac $\alpha 2-6(G a l \beta 1-4 G l c N A c \beta 1-3)_{2}$. 

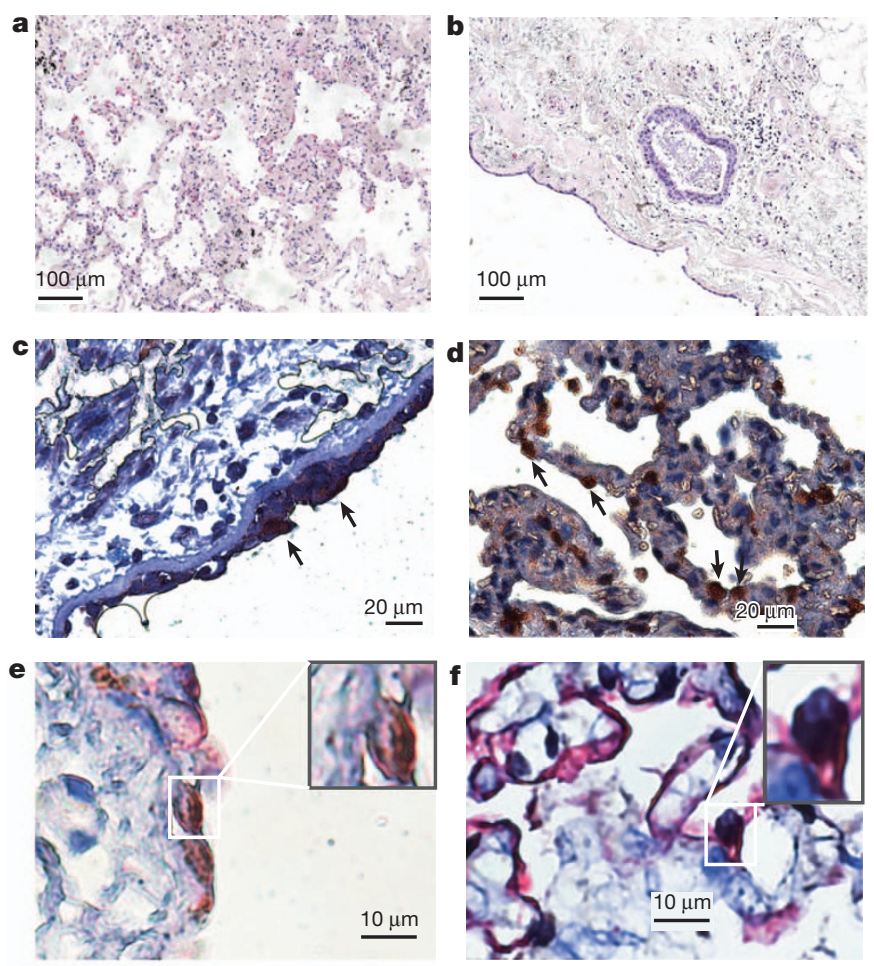

$10 \mu \mathrm{m}$
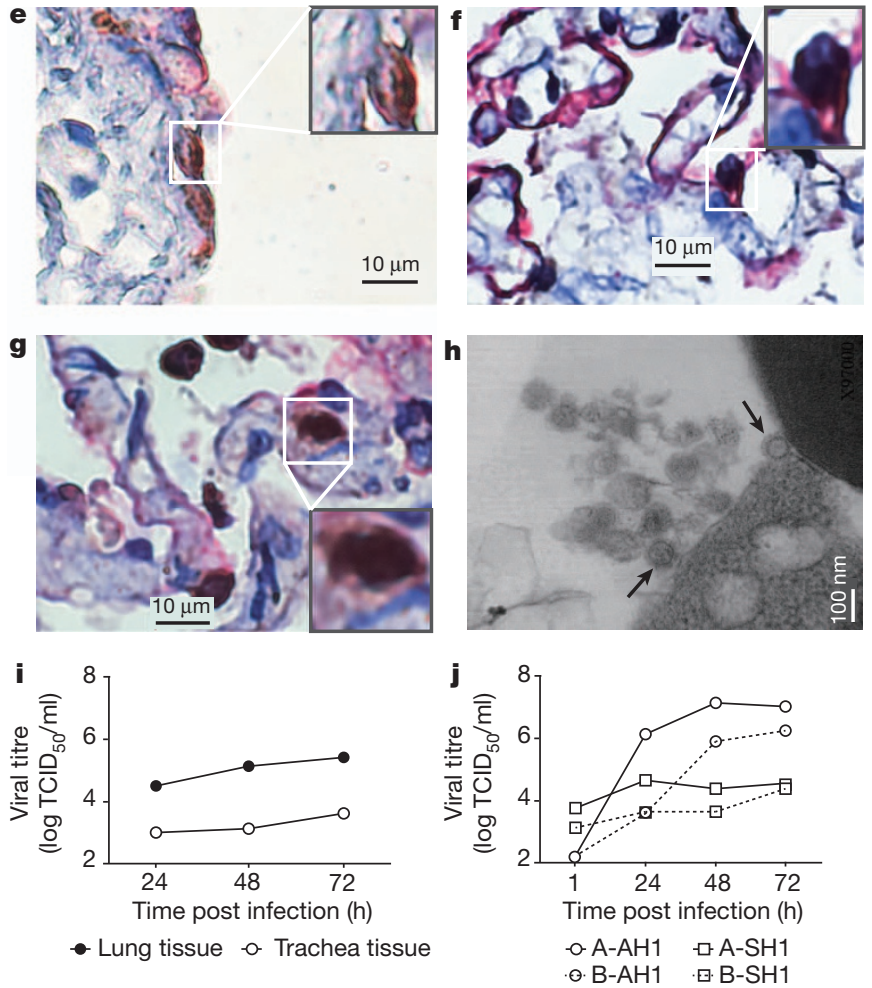

Figure $2 \mid$ Ex vivo infection of trachea or lung tissue with A/Anhui/1/2013 (AH1) or A/Shanghai/1/2013 (SH1). a, b, Trachea (a) and lung (b) explants without infection. c, d, Influenza nucleoprotein (brown, arrows) detected in trachea (c) and lung (d). e-g, Nucleoproteins in trachea epithelia/pneumocytes (e, f; red, cytokeratin staining) and type II pneumocytes (g) (red, surfactant staining). h, Extracellular viral particles (arrows) in AH1-infected lung detected by transmission electron microscopy. i, Viral replication in AH1-infeted lung/ trachea tissues from one donor (filled/empty circle, respectively). $\mathbf{j}$, Viral yields of lung fragments from two additional donors (A/B, solid/dotted line, respectively) infecting $\mathrm{AH} 1$ (circle) and $\mathrm{SH} 1$ (square). Original magnifications: $\times 10(\mathbf{a}, \mathbf{b}), \times 40(\mathbf{c}, \mathbf{d})$ and $\times 100(\mathbf{e}-\mathbf{g})$.

H7N9 viruses bound to long $\alpha 2,6$ glycans ( $\alpha 2-6$ SLN-LN) efficiently (Fig. 1). Long $\alpha 2-6$ oligosaccharides with an umbrella-like topology, which are rich in human and swine respiratory epithelial cells, are involved in the adaptation and infection of influenza viruses in these hosts $^{5,14,15}$. The increased preference of the H7N9 virus for human-type receptors may result in its higher cross-species transmissibility than the H5N1 viruses, which prefer avian-type receptors. This receptor specificity had been considered to be responsible for the major species barrier preventing $\mathrm{H} 5 \mathrm{~N} 1$ from efficient infection and transmission in humans. a
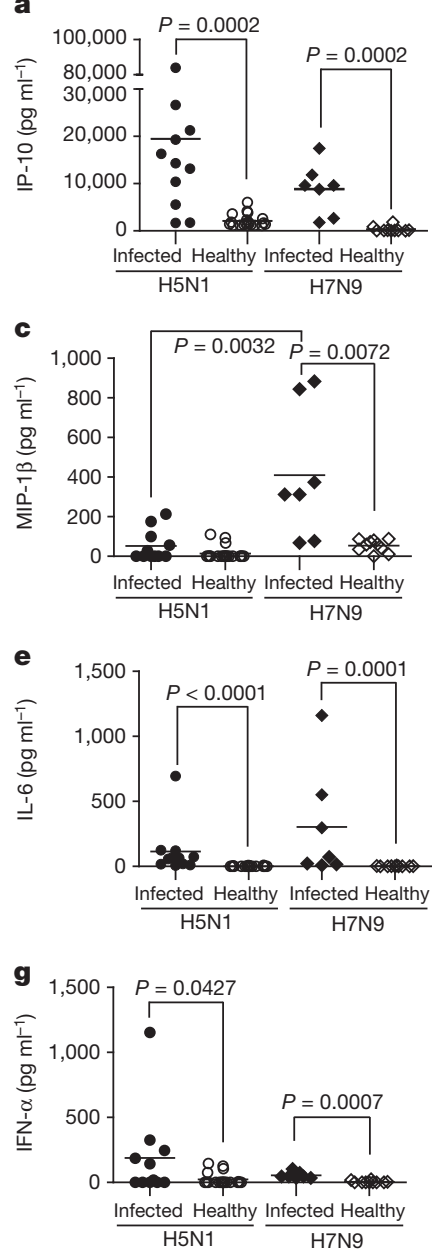
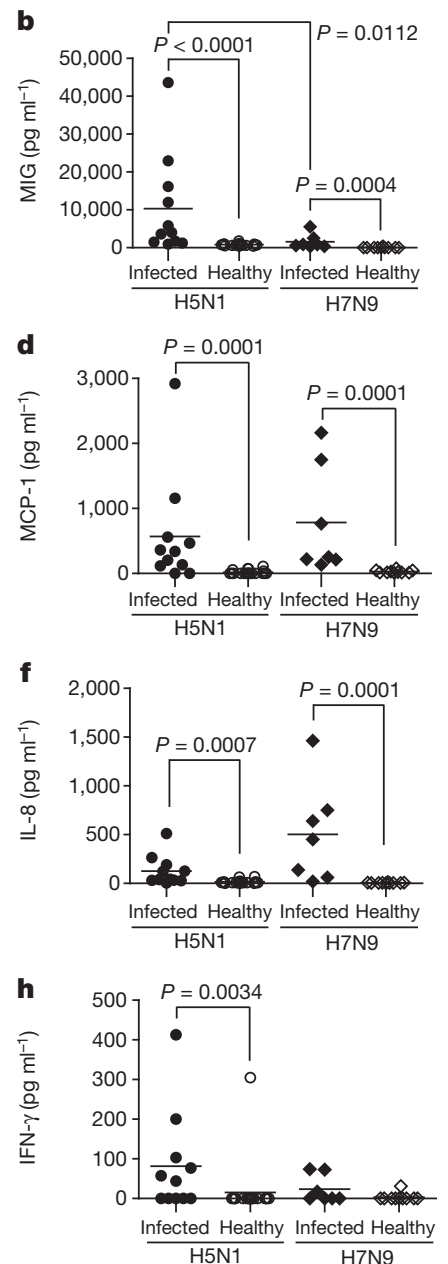

Figure 3 | Sera chemokine/cytokine levels of acutely infected patients by avian H7N9 or H5N1 viruses. $\mathbf{a}-\mathbf{h}$, Sera concentrations of the chemokines and cytokines IP-10 (a), MIG (b), MIP-1 $\beta$ (c), MCP-1 (d), IL-6 (e), IL-8 (f), IFN- $\alpha$ $(\mathbf{g})$ and IFN- $\gamma(\mathbf{h})$ were measured using cytometric bead-array assays according to the manufacturers' instructions. Results are presented as mean \pm s.e.m. from the specimens of $11 \mathrm{H} 5 \mathrm{~N} 1,7 \mathrm{H} 7 \mathrm{~N} 9$ and 30 close contacts tested in duplicate. $P$ values are shown on the figure; differences between groups were tested using non-parametric Kruskal-Wallis analysis of variance (ANOVA) with Dunn's post-hoc test for multiple comparisons.

Human upper respiratory tissues and trachea contain mainly $\alpha 2,6$ receptors, whereas lung tissues contain a mixture of $\alpha 2,3$ - and $\alpha 2,6$ linked siallic acid ${ }^{5,14}$. To assess the effect of dual-receptor binding of the H7N9 virus to human respiratory tracts, sections of tracheal and lung explants were infected. We found that the epithelial cells in the human lower respiratory tract and type II pneumocytes in the alveoli were susceptible for H7N9 virus infections, as evidenced by the expression of viral nucleoprotein (Fig. 2c-g). Extracellular viral particles were also observed in infected lung tissues at 24 hours post infection (h.p.i.) by transmission electron microscopy (Fig. 2h). Productive viral infection in the trachea and lung was demonstrated by increased viral yields in culture supernatants. Notably, the virus titre in lung tissues was about tenfold higher than that in tracheal tissues (Fig. 2i), which was consistent with the results of nucleoprotein staining (Fig. 2c, d). Efficient replication of the H7N9 virus in type II pneumocytes may cause lung function to deteriorate ${ }^{16}$, as seen with the $\mathrm{H} 5 \mathrm{~N} 1$ virus $^{17}$. Lower viral yields in the trachea may be associated with the inefficient humanto-human transmission. Although $\mathrm{AH} 1$ and $\mathrm{SH} 1$ show common high binding preferences to $\alpha 2,3$ glycans, a more productive replication of AH1 in lung tissues was observed, with a peaking titre around 100-fold higher than that of SH1 (Fig. 2j). This indicated that viral replications in respiratory tissues are not solely determined by receptor-binding 
Table 1 | Cross-reactive antibody response against the H7N9 virus

\begin{tabular}{|c|c|c|c|c|c|c|c|c|c|c|}
\hline \multirow[t]{2}{*}{ Age group } & \multirow[t]{2}{*}{ Subjects } & \multirow{2}{*}{$\begin{array}{l}\text { Age distribution } \\
\text { (years) }\end{array}$} & \multirow[t]{2}{*}{ Antigen } & \multirow{2}{*}{$\begin{array}{c}\text { Increase in antibody } \\
\text { titre by a factor of } \geq 4 \\
(\%)\end{array}$} & \multicolumn{2}{|c|}{ Geometric mean titre } & \multicolumn{2}{|c|}{ Titre $\geq 40$ (\%) } & \multicolumn{2}{|c|}{ Titre $\geq 160(\%)$} \\
\hline & & & & & $\begin{array}{c}\text { Before } \\
\text { vaccination }\end{array}$ & $\begin{array}{c}\text { After } \\
\text { vaccination }\end{array}$ & $\begin{array}{c}\text { Before } \\
\text { vaccination (\%) }\end{array}$ & $\begin{array}{c}\text { After } \\
\text { vaccination (\%) }\end{array}$ & $\begin{array}{c}\text { Before } \\
\text { vaccination (\%) }\end{array}$ & $\begin{array}{c}\text { After } \\
\text { vaccination (\%) }\end{array}$ \\
\hline \multirow[t]{4}{*}{ Children } & 30 & $3-5$ & CA07 & 76.7 & 20.5 & 272.2 & 43.3 & 80.0 & 10.0 & 73.3 \\
\hline & & & Vic361 & 36.7 & 55.3 & 152.8 & 73.3 & 93.3 & 16.7 & 60.0 \\
\hline & & & HB158 & 86.7 & 36.5 & 432.1 & 63.3 & 96.7 & 13.3 & 83.3 \\
\hline & & & $\mathrm{AH} 1$ & 0 & $<5$ & $<5$ & 0 & 0 & 0 & 0 \\
\hline \multirow[t]{4}{*}{ Adults } & 30 & $18-59$ & CA07 & 70.0 & 14.8 & 156.3 & 26.7 & 76.7 & 0 & 60.0 \\
\hline & & & Vic361 & 53.3 & 9.8 & 38.2 & 13.3 & 70.0 & 0.0 & 13.3 \\
\hline & & & HB158 & 80.0 & 28.9 & 259.9 & 53.3 & 96.7 & 10.0 & 76.7 \\
\hline & & & $\mathrm{AH} 1$ & 0 & $<5$ & $<5$ & 0 & 0 & 0 & 0 \\
\hline \multirow[t]{4}{*}{ Older people } & 30 & $\geq 60$ & CA07 & 46.7 & 10.5 & 52.8 & 10.0 & 53.3 & 0 & 30.0 \\
\hline & & & Vic361 & 40.0 & 25.8 & 68.1 & 40.0 & 90.0 & 0.0 & 30.0 \\
\hline & & & HB158 & 60.0 & 33.2 & 211.1 & 63.3 & 93.3 & 6.7 & 53.3 \\
\hline & & & $\mathrm{AH} 1$ & 0 & $<5$ & $<5$ & 0 & 0 & 0 & 0 \\
\hline
\end{tabular}

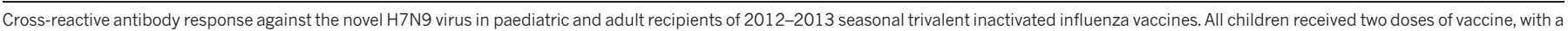

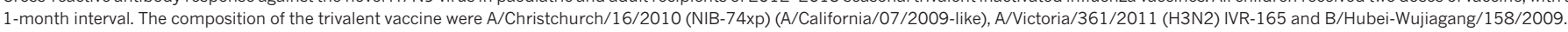
AH1, A/Anhui/1/2013 (H7N9); CA07, A/California/07/2009 (H1N1); HB158, B/Hubei-Wujiagang/158/2009; Vic361, A/Victoria/361/2011 (H3N2).

properties, but that other factors, such as viral polymerase and host factors, may also have a role. Moreover, H7N9 isolates demonstrated advanced growth capabilities in human, porcine and canine cell lines that were comparable to that of the pandemic 2009 H1N1 virus (Supplementary Fig. 2).

The dysfunction of the chemokine and cytokine response is considered to be associated with severe human $\mathrm{H} 5 \mathrm{~N} 1$ infection $^{18,19}$. Therefore, we measured the concentrations of chemokines and cytokines in acute sera from seven patients infected with H7N9 by cytometric beads array (detailed sampling information shown in Supplementary Table 3). The levels of IP-10, MIG, MIP-1 $\beta$, MCP-1, IL-6, IL- 8 and IFN- $\alpha$ were significantly higher in patients with $\mathrm{H} 7 \mathrm{~N} 9$ than in healthy subject controls (Fig. 3). No significant differences were detected between patients with H7N9 and H5N1, with the exception of the MIG and MIP-1 $\beta$ levels. The MIG response was significantly lower in patients with H7N9 than with $\mathrm{H} 5 \mathrm{~N} 1$, whereas the MIP- $1 \beta$ response was significantly higher in patients with $\mathrm{H} 7 \mathrm{~N} 9$ than with $\mathrm{H} 5 \mathrm{~N} 1$ (Fig. 3). The hypercytokinaemia in patients with $\mathrm{H} 7 \mathrm{~N} 9$ may be one of the important contributors to clinical severity, as seen in $\mathrm{H} 5 \mathrm{~N} 1$ infections ${ }^{20}$. Notably, most of the severe H7N9 cases were in old adults ( $\geq 60$ years), which might be due to the enhanced expression of chemokine receptor related to ageing or chronic diseases, as observed previously ${ }^{21-24}$.

Pre-existing immunity in the general population is one of the determining factors for the susceptibility to a novel influenza virus. In the event of H7N9 virus, little is known about the level of pre-existing or crossreactive immunity in humans. We measured haemagglutination inhibition (HAI) and neutralization antibody responses against the H7N9 virus in different age groups (children, 3-5 years old; adults, 18-59 years old, and old people, $\geq 60$ years old) of pre- and post-seasonal influenza vaccination. No pre-existing immunity was detected in serum samples of all age groups. Also, no detectable cross-reactive antibodies against the H7N9 virus were present in all age groups after current seasonal vaccination (Table 1 and Supplementary Table 1). These data demonstrated that the human population is naive to the H7N9 virus, and current seasonal vaccination does not protect against $\mathrm{H} 7 \mathrm{~N} 9$ infection.

The antiviral drugs M2 ion channel blockers (amantadine and rimantadine) and neuraminidase inhibitors (oseltamivir, zanamivir, peramivir and laninamivir) are available at present for the prophylaxis and treatment of influenza virus infection. However, the H7N9 isolates contain one M2 blocker resistance-related mutation (Ser31Asn). Tested by our in vitro neuraminidase function assay, current $\mathrm{H} 7 \mathrm{~N} 9$ viruses are found to be sensitive to both oseltamivir and zanamivir (Supplementary Table 2). However, the antiviral resistance in A/H7N9 viruses should be a concern, as neuraminidase inhibitor-resistance mutants associated with a neuraminidase Arg292Lys substitution were recently observed in two patients infected with H7N9 and correlated with adverse clinical prognosis $^{25}$.
Although no efficient human-to-human transmission has occurred, biological features we demonstrated here, such as a dual receptorbinding preference and high growth ability, provide the H7N9 virus with higher transmissibility from avian to human. Together with the challenges in the available treatments for H7N9 infection caused by its clinical severity and emerging antiviral resistance, further unpredictable evolution and adaptation of the H7N9 virus and the lack of preexisting immunity leave the human population at high risk. Thus, the threats of the H7N9 virus with pandemic potential should not be underestimated and intensive surveillance must be undertaken.

\section{METHODS SUMMARY}

Viruses and cells. All H7N9 avian influenza viruses were isolated and passaged in 9-day-old embryonated specific pathogen-free chicken eggs. All experiments with H7N9 viruses were performed in approved enhanced biosafety level 3 (BSL-3) containment laboratories. Human type II alveolar epithelial (A549) cells were maintained in DMEM, and Madin-Darby canine kidney (MDCK) and porcine kidney (PK15) cells were maintained in MEM, supplemented with $10 \%$ FBS, glutamine, HEPES, penicillin and streptomycin.

Direct binding assay with synthetic sialylglycopolymers. As described elsewhere ${ }^{5}$, serial dilutions of sialylglycopolymers in PBS were coated in 96-well flat-bottom polystyrene plates overnight at $4{ }^{\circ} \mathrm{C}$. Thirty-two haemagglutination unit (HAU) live viruses per well, and oseltamivir carboxylate at a final concentration of $17.5 \mu \mathrm{M}$ were added, as described previously ${ }^{26}$. After incubating with appropriate amounts of the primary antibodies, the secondary antibody was added, and bound antibody was detected using tetramethylbenzidine substrate solution.

Ex vivo infection of human lung and tracheal tissue by the H7N9 virus. Tissue fragments were infected with $2 \times 10^{7} \mathrm{TCID}_{50}$ (the tissue culture infectious dose affecting $50 \%$ of the cultures) A/Anhui/1/2013 virus for $24 \mathrm{~h}$ and $48 \mathrm{~h}$, and the infectivity was assayed by immunohistochemistry staining and morphology examination. For replication tests, the tissue fragments were infected with $10^{4} \mathrm{TCID}_{50}$ A/Anhui/1/2013 or A/Shanghai/1/2013 virus. The viral titres in the supernatants at 1, 24, 48 and 72 h.p.i. were measured in MDCK cells.

Cytokine and chemokine measurement. Sera concentrations of the chemokines and cytokines IP-10, MIG, MCP-1, MIP-1 $\beta$, IL-6, IL-8, IFN- $\alpha$ and IFN- $\gamma$ were measured using cytometric bead-array assays according to the manufacturers' instructions. Cross-reactive antibody assay. A total of 90 stored serum samples vaccinated with seasonal influenza vaccines between 2012 and 2013 were tested for antibody responses to the novel H7N9 subtype A/Anhui/1/2013 virus.

Full Methods and any associated references are available in the online version of the paper.

Received 1 May; accepted 14 June 2013.

Published online 3 July; corrected online 24 July 2013 (see full-text HTML version for details).

1. Gao, R. etal. Human infection with a novel avian-origin influenza A(H7N9) virus. N. Engl. J. Med. 368, 1888-1897 (2013).

2. World Health Organization. Avian influenza A(H7N9) virus. http://www.who.int/ influenza/human_animal_interface/influenza_h7n9/en/index.html (accessed, 31 May 2013). 
3. Gao, H. N. et al. Clinical findings in 111 cases of influenza A (H7N9) virus infection. N. Engl. J. Med. 368, 2277-2285 (2013).

4. Li, Q. et al. Preliminary report: epidemiology of the avian influenza A (H7N9) outbreak in China. N. Engl. J. Med. http://dx.doi.org/10.1056/NEJMoa1304617 (24 April 2013)

5. Chandrasekaran, A. et al. Glycan topology determines human adaptation of avian H5N1 virus hemagglutinin. Nature Biotechnol. 26, 107-113 (2008).

6. Connor, R. J., Kawaoka, Y., Webster, R. G. \& Paulson, J. C. Receptor specificity in human, avian, and equine H2 and H3 influenza virus isolates. Virology 205, 17-23 (1994).

7. Matrosovich, M. etal. Early alterations of the receptor-binding properties of $\mathrm{H} 1, \mathrm{H} 2$, and $\mathrm{H} 3$ avian influenza virus hemagglutinins after their introduction into mammals. J. Virol. 74, 8502-8512 (2000).

8. Srinivasan, K., Raman, R., Jayaraman, A., Viswanathan, K. \& Sasisekharan, R. Quantitative description of glycan-receptor binding of influenza a virus h7 hemagglutinin. PLOS ONE 8, e49597 (2013).

9. Nidom, C. A. et al. Influenza A (H5N1) viruses from pigs, Indonesia. Emerg. Infect. Dis. 16, 1515-1523 (2010).

10. Yang, H., Chen, L. M., Carney, P. J., Donis, R. O. \& Stevens, J. Structures of receptor complexes of a North American H7N2 influenza hemagglutinin with a loop deletion in the receptor binding site. PLoS Pathog. 6, e1001081 (2010).

11. Yamada, S. et al. Haemagglutinin mutations responsible for the binding of H5N1 influenza A viruses to human-type receptors. Nature 444, 378-382 (2006).

12. Herfst, S. et al. Airborne transmission of influenza A/H5N1 virus between ferrets. Science 336, 1534-1541 (2012).

13. Imai, M. et al. Experimental adaptation of an influenza $\mathrm{H} 5 \mathrm{HA}$ confers respiratory droplet transmission to a reassortant $\mathrm{H} 5 \mathrm{HA} / \mathrm{H} 1 \mathrm{~N} 1$ virus in ferrets. Nature $\mathbf{4 8 6}$, 420-428 (2012).

14. Walther, T. et al. Glycomic analysis of human respiratory tract tissues and correlation with influenza virus infection. PLoS Pathog. 9, e1003223 (2013).

15. Bateman, A. C. et al. Glycan analysis and influenza A virus infection of primary swine respiratory epithelial cells: the importance of NeuAc $\alpha 2-6$ glycans. J. Biol. Chem. 285, 34016-34026 (2010).

16. Pastva, A. M., Wright, J. R. \& Williams, K. L. Immunomodulatory roles of surfactant proteins A and D: implications in lung disease. Proc. Am. Thorac. Soc. 4, 252-257 (2007)

17. Gu, J. et al. H5N1 infection of the respiratory tract and beyond: a molecular pathology study. Lancet 370, 1137-1145 (2007)

18. de Jong, M. D. etal. Fatal outcome of human influenza A (H5N1) is associated with high viral load and hypercytokinemia. Nature Med. 12, 1203-1207 (2006).

19. Writing Committee of the Second World Health Organization Consultation on Clinical Aspects of Human Infection with Avian Influenza A (H5N1) Virus. Update on avian influenza A (H5N1) virus infection in humans. N. Engl. J. Med. 358, 261-273 (2008).

20. Chen, Y. et al. Human infections with the emerging avian influenza A H7N9 virus from wet market poultry: clinical analysis and characterisation of viral genome. Lancet 381, 1916-1925 (2013).

21. Tarazona, R. et al. Increased expression of NK cell markers on T lymphocytes in aging and chronic activation of the immune system reflects the accumulation of effector/senescent T cells. Mech. Ageing Dev. 121, 77-88 (2001).
22. Freeman, C. M Curtis, J.L. \& Chensue, S. W. CC chemokine receptor 5 and CXC chemokine receptor 6 expression by lung $\mathrm{CD}^{+}$cells correlates with chronic obstructive pulmonary disease severity. Am. J. Pathol. 171, 767-776 (2007)

23. Saetta, M. et al. Increased expression of the chemokine receptor CXCR3 and its ligand $\mathrm{CXCL} 10$ in peripheral airways of smokers with chronic obstructive pulmonary disease. Am. J. Respir. Crit. Care Med. 165, 1404-1409 (2002)

24. Shalekoff, S., Gray, G. E. \& Tiemessen, C. T. Age-related changes in expression of CXCR4 and CCR5 on peripheral blood leukocytes from uninfected infants born to human immunodeficiency virus type 1 -infected mothers. Clin. Diagn. Lab. Immunol. 11, 229-234 (2004)

25. Hu, Y. et al. Association between adverse clinical outcome in human disease caused by novel influenza A H7N9 virus and sustained viral shedding and emergence of antiviral resistance. Lancet http://dx.doi.org/10.1016/S0140 6736(13)61125-3 (29 May 2013).

26. Childs, R. A. et al. Receptor-binding specificity of pandemic influenza A (H1N1) 2009 virus determined by carbohydrate microarray. Nature Biotechnol. 27, 797-799 (2009)

Supplementary Information is available in the online version of the paper.

Acknowledgements This study was supported by the National Basic Research Program (973) of China (2011CB504704, to Y.S.), Emergency Research Project on human infection with avian influenza H7N9 virus from the National Ministry of Science and Technology (no. KJYJ-2013-01-01 to Y.S.), and National Mega-projects for Infectious Diseases (2013ZX10004611 to J.Z.). We would like to acknowledge the Consortium for Functional Glycomics for providing the glycans for the receptor-binding test. We thank the US Centre for Disease Control and Prevention (CDC) for providing the strains A/Washington/1/2007(H3N2, WT), A/Texas/12/2007(H3N2, E119V), A/California/7/2009 (2009pdmH1N1, WT) and A/North Carolina/39/2009 (2009pdmH1N1, H275Y), and for the antiviral drug susceptibility test. We thank C. Li for critical comments of the manuscript and proofreading. We thank L. Huang, X. Xing, X. Zeng, Y. Zhu, L. Liu, S. Yang, Z. Li and T. Liu for technical support. We thank the provincial CDCs including Fujian, Sichuan, Guangdong, Hunan, Hubei and Jiangxi for providing sera specimens of patients with H5N1. The contents of this article are solely the responsibility of the authors and do not necessarily represent the views of the China $\mathrm{CDC}$ or other organizations.

Author Contributions Y.S., S.W., Z.F., J.H., W.Y., G.F.G., G.W., D.L. and Y.W. designed the experiments and discussed the results; J.Z., D.W., R.G., T.B., K.Q., Y.L., S.Z., J.G., J.D., L.D. Y.Z., H.W., X.L., J.L., L.L., X.Z., X.L., W.H., L.W., H.B., L.X.,Y.C., C.X., S.W., Z.F., J.H.,W.Y. and J.S performed the experiments; B.Z., J.S., X.Q., Y.Z., Y.P., Y.Y., X.Z. and Y.S. collected and transferred samples and tissues. J.Z., D.W., R.G., L.Y. and W.Z. analysed data; J.Z., D.W., R.G.,Y.L., W.Z. and Y.S. wrote the manuscript. J.Z., D.W., R.G. and B.Z. contributed equally to this work.

Author Information Reprints and permissions information is available at www.nature.com/reprints. The authors declare no competing financial interests. Readers are welcome to comment on the online version of the paper. Correspondence and requests for materials should be addressed to Y.S. (yshu@cnic.org.cn). 


\section{METHODS}

Cell culture. Human type II alveolar epithelial (A549), Madin-Darby canine kidney (MDCK) and porcine kidney (PK15) cells were obtained from the American Type Culture Collection. A549 cells were maintained in DMEM (Invitrogen) and MDCK and PK15 cells were in MEM (Invitrogen), supplemented with 10\% FBS (Invitrogen), glutamine ( $2 \mathrm{mM}$; Invitrogen), HEPES (10 mM; Invitrogen), penicillin $\left(100 \mathrm{U} \mathrm{ml}^{-1}\right)$, and streptomycin $\left(100 \mu \mathrm{g} \mathrm{ml}^{-1}\right.$; Invitrogen).

Virus preparation, titration and infection. In view of the biosafety issues involved in handling H7N9 viruses, the experiments were conducted in approved enhanced biosafety level 3 (BSL-3) containment laboratories. The viruses were propagated in 9-day-old embryonated specific pathogen-free chicken eggs, by a first passage in the H7N9 strain. The allantoic fluid was collected at 48 h.p.i., aliquoted, and stored at $-80{ }^{\circ} \mathrm{C}$ until use. Infectious titres $\left(\mathrm{TCID}_{50}\right.$, the tissue culture infectious dose affecting $50 \%$ of the cultures) were performed in confluent MDCK cells and confirmed by haemagglutination assay.

Neuraminidase inhibitors. Oseltamivir carboxylate (4- $\mathrm{N}$-acetyl-5-amino-3-(1ethylpropoxy)-1-cyclohexane-1 carboxylic acid), the active metabolite of oseltamivir, was provided by Hoffmann-La Roche. Zanamivir (4-guanidino-Neu5Ac2en) was provided by GlaxoSmithKline.

Direct binding assay with synthetic sialylglycopolymers. Receptor specificity was investigated using biotinylated glycans including $3^{\prime}$-SLN, $3^{\prime}$-SLN-LN, 6'-SLN and $6^{\prime}$ SLN-LN (see legend to Fig. 1), which were obtained from the Consortium of Functional Glycomics through their resource request program. As described elsewhere ${ }^{5}$, serial dilutions of sialylglycopolymers in PBS were coated in 96-well flat-bottom polystyrene plates overnight at $4{ }^{\circ} \mathrm{C}$. Thirty-two haemagglutination unit (HAU) live viruses per well and oseltamivir carboxylate (Hoffmann-La Roche) at a final concentration of $17.5 \mu \mathrm{M}$ were added, as described previously ${ }^{26}$. After incubating with appropriate amounts of the primary antibodies, including a panel of rabbit sera against an Eurasian H7N7 virus isolated from the environment, A/California/07/09 (H1N1) and A/Anhui/01/2005 (H5N1) viruses, the secondary antibody was added (horseradish peroxidase (HRP)-conjugated goat anti-rabbit IgG; Santacruz Biotechnology), and bound antibody was detected using tetramethylbenzidine substrate solution (R\&D Systems). All procedures were performed at $4{ }^{\circ} \mathrm{C}$ to avoid the cleavage effects of neuraminidase on the binding.

Growth curves in vitro. A549, MDCK and PK15 cells were infected with A/Shanghai/1/2013, A/California/07/2009 or A/Anhui/1/2013 virus at a multiplicity of infection (MOI) of 0.001 . One hour after inoculation at $37^{\circ} \mathrm{C}$, at time point 0 , the cells were washed once with PBS, and fresh infection medium containing $2 \mathrm{mgl}^{-1} \mathrm{~N}$-p-tosyl-L-phenylalaninechloromethyl ketone-treated (TPCK) trypsin (Sigma) was added. The supernatants were sampled at 12, 24, 48, 72 and 96 h.p.i. and the viral titres in these supernatants were determined by endpoint titration in MDCK cells as described ${ }^{27}$.

Ex vivo infection of human lung and tracheal tissue by the H7N9 virus. Human tracheal and lung sections were obtained from one donor, and two additional lung fragments were obtained from another two donors of uninvolved portions of surgical resection samples from patients undergoing removal of lung tissue for possible carcinoma, and regions containing carcinoma or infection were excluded. All patients gave informed consent under a study approved by the Institutional Review Board of National Institute for Viral Disease Control and Prevention, China CDC. The tissues from each donor were cut into multiple 2-3-mm fragments and were infected with $\mathrm{A} /$ Anhui/1/2013 at a titre of $2 \times 10^{7} \mathrm{TCID}_{50}$ virus at $37^{\circ} \mathrm{C}$ for $24 \mathrm{~h}$ and $48 \mathrm{~h}$ and the infectivity was assayed by immunohistochemistry staining and morphology examination. As to the replication tests, the tissue fragments were infected with $10^{4} \mathrm{TCID}_{50} \mathrm{~A} /$ Anhui/1/2013 or A/Shanghai/1/2013 virus. One hour after inoculation at $37^{\circ} \mathrm{C}$, at time point 0 , the tissues were washed three times with $2 \mathrm{ml}$ PBS, and $500 \mu \mathrm{l}$ fresh infection medium containing $2 \mathrm{mgl}^{-1}$ TPCK trypsin was added. The supernatants were sampled at 1, 24, 48 and 72 h.p.i. and the viral titres in these supernatants were determined by endpoint titration in MDCK cells.

H\&E staining and immunohistochemistry. Routine haematoxylin and eosin (H\&E) staining was used to determine the histology of lung and trachea explants. To determine the viral infection in lung or bronchus tissues, immunohistochemical staining was performed on 4 - $\mu \mathrm{m}$-thick deparaffinized sections using monoclonal antibodies against the nucleoprotein of influenza A (VS2525, USCDC) by using a polymer-based colorimetric indirect immunoalkaline phosphatase method (Thermo Scientific/Lab Vision). Sequential tissue sections incubated with normal serum pertinent to the primary antibody were used as negative controls. Paraffinembedded sections were deparafinized by two washes in xylene and were rehydrated through decreasing concentration of ethanol. After washing with PBS for $5 \mathrm{~min}$ at room temperature, sections were treated with $200 \mu \mathrm{g} \mathrm{ml}^{-1}$ proteinase $\mathrm{K}$ for $20 \mathrm{~min}$. After blocking with UV blocking buffer (Thermo Scientific/Lab Vision), the sections were incubated with specific antibodies for $30 \mathrm{~min}$ at room temperature. Unbound antibody was removed by $0.5 \%$ PBS tween-20 (PBST) before adding HRP-labelled polymer for $15 \mathrm{~min}$ at room temperature (Thermo Scientific/Lab Vision). After washing unbound labelled polymer, peroxidase staining in tissue sections was revealed by DAB solution (Thermo Scientific/Lab Vision). Double-stain immunohistochemistry was performed using peroxidase polymerlabelled antibodies (Thermo Scientific/Lab VisionDako) against cytokeratin AE1/ AE3 (188132, Invitrogen) as the marker for epithelial cells, surfactant protein A as the marker for type II pneumoncytes (ab51891, abcam) on the sections with the nucleoprotein staining, followed by the mouse anti-influenza A nucleoprotein antibody labelled with immunoalkaline phosphatase polymer. All staining steps were completed on an automatic staining system (DAKO, Denmark). After stopping the reaction in running water, sections were counterstained by a quick dip in a Mayer's haematoxylin solution. The sections were mounted with DPX and examined by light microscopy (ZEISS M2).

Cytokine and chemokine measurement. Sera concentrations of the chemokines/ cytokines IP-10, MIG, MCP-1, MIP-1 $\beta$, IL-6, IL-8, IFN- $\alpha$ and IFN- $\gamma$ from seven patients with $\mathrm{H} 7 \mathrm{~N} 9$ and ten close contacts were measured using cytometric beadarray assays (CBA; Becton Dickinson) according to the manufacturers' instructions. Fifty microlitres of tested sera or sera diluents in assay diluent was incubated with $50 \mu \mathrm{l}$ capture beads suspension of each flex set kit per test at room temperature for $1.5 \mathrm{~h}$, and then $50 \mu \mathrm{l}$ phycoerythrin-conjugated detection reagent was added for another $1.5 \mathrm{~h}$. After washing in $1 \mathrm{ml}$ wash buffer, the samples were run and FACS data were collected using a FACSAria I flow cytometer and analysed using BD Cytometric Bead Array 1.4 software. The data together with those of 11 confirmed patients with $\mathrm{H} 5 \mathrm{~N} 1$ and 20 close contacts previously measured by $\mathrm{CBA}$ were analysed.

Cross-reactive antibody assay. We assessed the level of cross-reactive antibody to H7N9 virus in 90 subjects before and after they had been vaccinated with the 2012-2013 seasonal influenza vaccines. The compositions of the trivalent vaccine were A/Christchurch/16/2010 (H1N1), A/Victoria/361/2011 (H3N2) and $\mathrm{B} /$ Hubei-Wujiagang/158/2009. The HAI assay was according to standard protocols with $0.5 \%$ turkey red blood cells (TRBCs) and a microneutralization assay as the standard protocols were performed ${ }^{28,29}$. Both HAI and microneutralization titres of 20 or more were defined as seropositive. We tested the samples for antibody responses to the novel H7N9 subtype viruses A/Anhui/1/2013. Before the HAI assay, serum samples were treated with a 1:4 (v/v) dilution of receptordestroying enzyme (RDE; Denka Seiken) at $37^{\circ} \mathrm{C}$ for $18 \mathrm{~h}$, followed by incubation at $56^{\circ} \mathrm{C}$ for $30 \mathrm{~min}$. The serum samples for the microneutralization assay were inactivated at $56^{\circ} \mathrm{C}$ for $30 \mathrm{~min}$. The acute and convalescent sera of two patients with $\mathrm{H} 7 \mathrm{~N} 9$ and animal sera against $\mathrm{H} 5 \mathrm{~N} 1$ or 2009 pdmH1N1 virus were included in the HAI and microneutralization tests as controls. For the HAI assay, 25- $\mu \mathrm{l}$ serial twofold sera diluents were incubated with standard virus of 4 HAU per $25 \mu \mathrm{l}$ at room temperature for $30 \mathrm{~min}$. Then, $50-\mu \mathrm{l}$ standardized $0.5 \%$ TRBCs were added, mixed well and settled at room temperature for the appropriate $30 \mathrm{~min}$. For the microneutralization assay, $50-\mu \mathrm{l}$ serial twofold sera diluents were incubated with standard virus of $100 \mathrm{TCID}_{50}$ per $50 \mu \mathrm{l}$ at $37^{\circ} \mathrm{C}, 5 \% \mathrm{CO}_{2}$ for $60 \mathrm{~min}$. Then, $100 \mu \mathrm{l} 1.5 \times 10^{4} \mathrm{MDCK}$ cells per well was added for a further $18 \mathrm{~h}$ at $37^{\circ} \mathrm{C}$, $5 \% \mathrm{CO}_{2}$. On day 2 , the cells were fixed by $80 \%$ cold acetone and stained by antiinfluenza A nucleoprotein monoclonal antibody pool (MAB8257 and MAB8258, Millipore) and peroxidase polymer-labelled goat anti-mice IgG (074-1802, Kirkegaard \& Perry Laboratories). Bound antibody was detected using freshly prepared $o$-phenylenediamine dihydrochloride and citrate buffer (Sigma). The test dose of virus is acceptable if the back-titration is positive in 5-7 wells containing the lowest dilution of test virus.

Neuraminidase inhibition assay. Fluorimetric neuraminidase activity assays were done according to the manufacturers' instructions of the NA-FluorTM kit (Life Technologies). In brief, a standardized dose of viruses was incubated with various concentrations of oseltamivir carboxylate or zanamivir in assay buffer containing 2-( $N$-morpholino) ethanesulphonic acid and calcium chloride, for $45 \mathrm{~min}$ at $37^{\circ} \mathrm{C}$. Then, substrate methylumbelliferyl- $\mathrm{N}$-acetylneuraminic acid (MUNANA) was added as a fluorescent substrate to this mixture. After incubation for another hour at $37^{\circ} \mathrm{C}$, stop solution was added to the mixture to stop the reaction. The fluorescence signal was measured at an excitation wavelength of $360 \mathrm{~nm}$ and an emission wavelength of $465 \mathrm{~nm}$, and the 50\% inhibitory concentrations $\left(\mathrm{IC}_{50}\right)$ of antiviral drugs were calculated according to the concentration required for reducing neuraminidase activity by $50 \%$ by analysis with GraphPad Prism software, version 5 (GraphPad Software).

Electron microscopic examination. The infected lung tissues with H7N9 virus were processed for transmission electron microscopy at $24 \mathrm{~h}$ post infection ex vivo as previously described ${ }^{30}$. The AH1-infected lung tissues were cut into several 1 - $\mathrm{mm}$ fragments and immerged in fixative ( $2 \%$ paraformaldehyde, $2.5 \%$ glutaraldehyde, $0.1 \%$ sodium cacodylate buffered, $\mathrm{pH} 7.2)$ for $1 \mathrm{~h}$ at $4{ }^{\circ} \mathrm{C}$. Tissues were then fixed in $1 \%$ osmium tetroxide ( $0.1 \%$ sodium cacodylate buffered, $\mathrm{pH} 7.2)$ for $1 \mathrm{~h}$ at $4{ }^{\circ} \mathrm{C}$. After several dehydrations and rehydrations, the blocks were infiltrated 
with 1:1 (v/v) ethanol/epoxy resin (SPI-Chem low viscosity "Spurr" kits) for $1 \mathrm{~h}$ at room templerature following Spurr medium infiltration and embedded in BEEM embedding capsules with Spurr medium. Cured blocks were cut into ultrathin sections with a microtome (LKB Nova) and mounted on copper grids (150 meshes). The sections were stained with $1 \%$ uranyl acetate in $50 \%$ ethanol for $10 \mathrm{~min}$ and $0.2 \%$ lead citrate for $5 \mathrm{~min}$, and then observed under transmission electron microscope (FEI Tecnai12) at $80 \mathrm{kV}$.

Statistical analysis. Statistical significance was determined using non-parametric tests and the GraphPad Prism 5 software package (GraphPad Software). $P<0.05$ was deemed to indicate statistical significance.
27. Reed, L. J. \& Muench, H. A simple method of estimating fifty percent endpoints. Am. J. Hyg. 27, 493-497 (1938).

28. WHO. Collaborating Centers from Reference and Research on Influenza. Concepts and Procedures for Laboratory-Based Influenza Surveillance 17-35 (U.S. Department of Health and Human Services, 1982).

29. WHO Global Influenza Surveillance Network. Manual for the laboratory diagnosis and virological surveillance of influenza; http://whqlibdoc. who.int/ publications/2011/9789241548090_eng.pdf.

30. Goldsmith, C. S. et al. Elucidation of Nipah virus morphogenesis and replication using ultrastructural and molecular approaches. Virus Res. 92, 89-98 (2003). 